\title{
Moral concerns and consumer choice of fresh and processed organic foods
}

\author{
Moira Dean, Monique M Raats and Richard Shepherd \\ Department of Psychology \\ University of Surrey, UK.
}

All correspondence should be addressed to the first author at the Department of Psychology, University of Surrey, Guildford, Surrey GU2 7XH, UK (e-mail: moira.dean@surrey.ac.uk).

This work has been carried out with financial support from the Commission of the European Communities, specific RTD program "Quality of Life and Management of Living Resources", QLK1 $2002-02446$ "Consumer decision making on organic products (CONDOR)". It does not necessarily reflect its views and in no way anticipates the Commission's future policy in this area. 


\section{Introduction}

The organic market in the UK has grown rapidly in recent years and is now one of the biggest in the world (Commission of the European Committees, 2004). There have been many studies investigating the reasons consumers give for choosing organic foods (see Shepherd, Magnusson and Sjoden, 2005, for a review). Many of these studies have taken the form of asking directly for reasons for choice rather than modeling how beliefs, attitudes and other variables predict intention or behavior. This earlier literature has also concentrated on fresh organic foods, mainly in the form of fruits and vegetables and to a lesser extent on fresh meat and milk. Although this reflects the market for organic foods in its early stages, with most of the consumption of organic foods concentrated on fresh produce (Klont, 1999), markets have begun to extend to processed and convenience foods (Klont, 1999).

This move into processed organic foods opens a series of questions concerning consumer attitudes and motivations. When organic produce is sold fresh, people can identify with these foods as being 'organic'. However, if ingredients are combined and processed, people's understanding of organic might be very different. Consumer beliefs and attitudes on this have not previously been studied. Also consumers' beliefs about organic foods include the idea that they are 'natural' and therefore not processed to any great degree and therefore the types of factors influencing choice of organic fresh foods might be quite different from those predicting the choice of processed organic foods.

The Theory of Planned Behavior (TPB) is one of the widely applied expectancy-value models used to predict and explain human behavior in the area of food choice (Beale and Manstead, 1991; Sparks, Hedderley and Shepherd, 1992; Sparks and Shepherd, 1992; Towler and Shepherd, 1992; Lloyd, Paisley and Mela, 1993; Raats, Shepherd and Sparks, 1995; Sparks, Shepherd and Frewer, 1995; Thogersen, 2002; Sparks and Shepherd, 2002). According to this theory, human behavior is a function of behavioral intention which is formed by the combination of attitudes towards the behavior, subjective norms and the person's perception of behavioral control. Attitudes towards the behavior are said to be determined by salient underlying beliefs weighted by the perceived likelihood of salient outcomes occurring with the value attached to those particular outcomes (Ajzen and Fishbein, 2000). Meta analysis undertaken by Armitage and Conner (2001) found support for the efficacy of the TPB as a predictor of intentions and behavior. Results showed that although prediction was better for self-reported than observed behavior, the TPB was capable of explaining $20 \%$ of variance in a prospective measure of actual behavior. Also PBC independently predicted intention and behavior in a wide range of domains.

Despite the success of TPB in the area of health and food choice the elicitation procedures for obtaining attitudes have been criticized by many researchers for often neglecting affective factors (Conner and Sparks, 1996). This is true even for health behaviors where affective attitudes are found to be better predictors than evaluative measures of attitude (Ajzen and Timko, 1986). In other areas of research a number of studies have looked at affective outcomes (e.g. regret, pleasure) as distinct from cognitive outcomes as determinants of attitudes (Bagozzi, 1989; Ajzen and Driver, 1991; Richard, van der Pligt and de Vries, 1995). For example, Ajzen and Driver (1991) showed for leisure activities, such as going to the beach, jogging, skiing, etc people evaluate their behavior in terms of instrumental costs and benefits as well as the positive and negative feelings these behaviors evoke. They found that for most of these activities affective attitude was a stronger predictor of intention that cognitive attitude although separating measures of attitude did not significantly improve prediction of leisure intention (Ajzen, 1991; p 203). Conner and Sparks (1996) claim that food consumption is a heavily affectively laden area and argue for greater development of affect within the TPB structure. Despite this most researchers in the area of food choice address attitudes as a joint entity (Armitage and Conner, 1999) without investigating the unique contribution affect and cognition make to the intended behavior. The present study compares the intention to buy organic foods using separate cognitive and affective components of attitude with the measure obtained by combining the two, to see whether the predictive power of the model can 
be improved with separate measures and the specific contribution made by each attitude component.

In addition to the original variables suggested by Ajzen and Fishbein a number of others, such as anticipated affect (Richard, 1994), self identity (Biddle, Bank and Slavings, 1987; Charng, Piliavin and Callero, 1988; Sparks and Shepherd, 1992), perceived need (Paisley and Sparks,1998) and moral norms (Manstead, 2000) have been added to the TPB with both theoretical and empirical justifications. Work undertaken with the addition of moral norms has increased the predictive power of the model in areas as diverse as bone marrow donation (Schwartz and Tessler, 1972), shoplifting and exam-cheating (Beck and Ajzen, 1991), traffic violations (Manstead, 2000), energy conservation (Black, Stern and Elworth, 1985), recycling (Guagnano, Stern and Dietz, 195; Thøgersen, 1996), littering (Heberlein, 1972), environmentally friendly buying (Thøgersen, 1996) and organic wine purchase (Thøgersen, 2002). However, in each study moral norm has been operationalized differently, as personal norms, moral obligation, and ethical beliefs thus making comparisons between studies difficult (Sparks and Shepherd, 2002).

In some of the research into food choice, moral norms (personal beliefs about right and wrong) were found to be a significant independent predictor of intentions and behaviors as well as attitudes (Raats et al, 1995; Sparks et al., 1995; Sparks and Shepherd, 2002). Sparks et al.'s study (1995) showed that ethical concern was a significant predictor of people's attitude towards genetically modified foods. Raats et al. (1995) looking at mothers' attitudes towards food consumption of children found that the addition of moral obligation significantly improved the predictive power of the model. Finally, Sparks and Shepherd (2002) showed that in the area of genetic modification relating to food, moral obligation had a predictive effect on behavioral intentions as well as an independent effect on attitudes. Manstead (2000) argues that in domains where the purchase of consumer products impact upon the welfare of others or where there is conflict between moral norms (or perceived obligations) and attitudes, moral norms would be expected to have a predictive effect on people's behavioral intentions. Thus in the area of organic food where there are conflicting views about the benefits and costs of organic vs conventional food production, we would expect moral norms to influence both attitudes and intentions. However, it is important to note that earlier research examined moral norms by looking at feelings of moral obligations and feelings of guilt arising from acting in a way that goes against people's principles and paid little attention to behaviors and intentions that were influenced by doing something because it was morally right. Specifically in the case of organic foods it could be argued that one's intention to buy could be influenced not only by obligation and guilt but also by wanting to do something that is morally and ethically good. Thus in this study we investigate whether positive moral norms as well as negative moral norms have predictive power over and above attitudes, subjective norm and perceived behavioral control.

The study aims to test how measures of affective attitudes and measures of positive and negative morals could be integrated into the Theory of Planned Behavior in the domain of organic food choice to evaluate their relative contributions to predict intention to purchase both fresh and processed organic foods.

\section{METHOD}

\section{Respondents}

Two hundred and eighty one ( $77 \%$ women, $23 \%$ men) members of the public completed the questionnaires in exchange for payment $(\mathbf{f 1 0 . 0 0 )}$ ). To ensure sufficient variation across the components to be analyzed, the participants were selected using stratified random sampling. The stratification criteria were: 1 ) each respondent is at least partially responsible for the family's grocery shopping, 2 ) at least $30 \%$ of the respondents use organic food weekly, 3 ) there is roughly 
the same percentage of respondents in each of the age groups 18 - 30 years, 31 - 45 years and 46 65 years.

\section{Materials and procedure}

In the elicitation phase of the research, participants $(n=50)$ were given a belief elicitation questionnaire. Here participants were asked the following questions: (i) 'What advantages (if any) do you see in buying organic apples? ; (ii) What disadvantages (if any) do you see in buying organic apples? ; (iii) We are interested in how buying organic apples makes you feel. Please provide a list of all the emotions that you experience when you think about buying organic apples; (iv) What else do you associate with buying organic apples? These questions were framed according to the method described by Ajzen and Fishbein (1980) with question number three adapted from Esses and Maio (2002). Spaces were provided after each question for participants to record their answers. Similar structured questions were asked with respect to buying ready-to-cook organic pizza. The presentation order of the two sets of questions was reversed for half the sample.

The main questionnaire consisted of the following measures for two types of organic products, fresh and processed, to assess the central components of TPB. Organic apple was chosen as an example of a fresh product and organic ready-to-cook pizza as a processed convenience food. The examples of the items provided below represent the common structure of questions for both products. Seven-point scales were used unless otherwise indicated; response options are indicated in parentheses, as are scale values where relevant.

Behavioral beliefs were measured with eight questions: "Buying organic apples instead of conventional apples would mean... (1) "more expensive apples", (2) "apples free from chemicals such as additives, or residues from fertilizers, pesticides or herbicides", (3) "more healthy apples", (4) "better tasting apples", (5) "better looking apples", (6) "apples that have been produced in a way that is better for the environment", (7) "more natural apples" and (8) "I can trust how the apples have been produced" (strongly disagree to strongly agree).

Attitudes were measured with four semantic differential scales, two to reflect affective attitude and two for cognitive attitude. Affective attitude was measured with "Buying organic apples instead of conventional apples would make me feel..." (not contented to contented and not pleased to pleased) and cognitive attitude with "I think that buying organic apples instead of conventional apples is..." (harmful to beneficial and foolish to wise).

Perceived behavioral control (PBC) was measured with two items, referring to difficulty: "For me buying organic apples instead of conventional apples is..." (easy to difficult) - and control: "If I wanted to, it would be possible for me to buy organic apples instead of conventional apples" (strongly disagree to strongly agree) (Sparks et al., 1997).

Subjective norm was assessed with two items: "Most people who are important to me would think that I (should not to should) buy organic apples instead of conventional apples" and "Most people who I value would buy organic apples instead of conventional apples..." (strongly disagree to strongly agree).

Moral norms were measured by six items on 7-point scales from strongly disagree to strongly agree. To assess negative moral norms (obligations) the items were: "It would be morally wrong for me to buy organic apples instead of conventional apples", "Buying organic apples instead of conventional apples would go against my principles" and "I would feel guilty if I bought organic apples instead of conventional apples". To assess positive moral norms the items were: "Buying organic apples instead of conventional apples would..." (a) "feel like making a personal contribution to something better", (b)"feel like the morally right thing" and (c) "make me feel like a better person". 
Purchase intention was measured with two items. First there was one 7-point scale question which took the following form: "If it is available locally, I intend to buy organic apples instead of conventional apples the next time I buy apples" ( 1 =very unlikely to $7=$ very likely). The second item asked respondents to circle the most suitable number from zero to six to answer the question: "Of the next six times you buy apples, how many times would you buy organic apples if available locally?".

The questionnaire also included a set of demographic and shopping behavior questions.

\section{Results}

\section{Demographics}

Twenty per cent of the sample had been buying organic for more than 5 years whereas $37 \%$ use organic regularly and $34 \%$ do not buy any organic food at all.

\section{Beliefs concerning organic apples and ready-to-cook organic pizza}

Participants were questioned on their beliefs about organic apples and organic pizza on eight items (see table 1 for means and standard deviations). Factor analysis (Principal axis factoring) with oblimin rotation was performed on the eight belief items relating to each product separately. Two factors were extracted (see table 2). For organic apple the first factor explained $49 \%$ of the variance and the second factor $17 \%$ and the items chemicals, healthy, environment, taste, natural and trust loaded on the same factor. The other factor mainly reflected beliefs about price and appearance. The mean value of the items loading on factor one was computed for each individual and labeled "beliefs about organic apples".

When the same procedure was repeated for belief items relating to organic ready-to-cook pizza the first factor explained $57 \%$ of the variance and the second factor explained $15 \%$ of the total variance (see table 3). All beliefs with the exception of appearance loaded on the first factor. The mean value of the seven items (with the exception of appearance) was computed for each individual and labeled "beliefs about organic pizza".

insert table 1 here

insert table 2 here

insert table 3 here

\section{The TPB and moral norms}

The TPB variables were formed by averaging the relevant items (see table 4 for means, standard deviations, correlations and reliability coefficients).

Insert table 4 here

In order to analyze whether the measures of moral norms are able to improve the prediction over and above the basic TPB variables, hierarchical regression analyses were performed. Intentions to purchase organic apples were regressed on affective attitude, cognitive attitude, perceived control, and subjective norms. Moral positive and moral negative norms were entered into the hierarchical analysis in a second step (see table 5).

insert table 5 here 
Multiple regressions of intention to purchase organic apple on affective attitudes, cognitive attitudes, subjective norms, positive moral norm and negative moral norm (adjusted $R^{2}=0.60$, $F(6,274)=68.80, p<0.0001)$ revealed significant independent effects for affective attitude $(\beta=$ $0.29, \mathrm{df}=280, p<0.001)$, cognitive attitude $(\beta=0.11, \mathrm{df}=280, \mathrm{p}=0.05)$, subjective norm $(\beta=0.10$, $\mathrm{df}=280, \mathrm{p}<0.05)$, perceived behavioral control $(\beta=0.18, \mathrm{df}=280, \mathrm{p}<0.001)$ and positive moral norm $(\beta=0.31, d f=280, p<0.001)$ but not for negative moral norm $(\beta=0.01, d f=280, n s)$. The increment in explained variance (change in $R^{2}$ ) from the first to second stage revealed it was significant $(p<0.0001)$ for intention to buy organic apples $(5 \%)$. This showed that for organic apple positive moral norm significantly increased prediction of intention although negative moral norm (doing the wrong thing when buying organic apples) did not.

Comparing the regression results using the total score of attitude with the regression of affect and cognition separately showed that there were no differences in the total variance explained or the contributions of these variables to intention (table 6).

insert table 6 here

Multiple regressions of intention to purchase organic ready-to-cook pizza (see table 7) on affective attitudes, cognitive attitudes, subjective norms, positive moral norm and negative moral norm (adjusted $R^{2}=0.39, F(6,274)=31.06, p<0.0001$ ) revealed significant independent effects for affective attitude $(\beta=0.18, d f=280, p<0.01)$, subjective norm $(\beta=0.16, d f=280, p<0.01)$, and positive moral norm $(\beta=0.31, \mathrm{df}=280, p<0.001)$ but not for cognitive attitude $(\beta=0.10, \mathrm{df}=280$, $\mathrm{ns})$, perceived behavioral control $(\beta=0.02, \mathrm{df}=280, \mathrm{~ns})$ or negative moral norm $(\beta=-0.07, \mathrm{df}=$ $280, \mathrm{~ns}$ ). The increment in explained variance (change in $\mathrm{R}^{2}$ ) from the first to second stage revealed it was significant $(p<0.0001)$ for intention to buy organic pizza $(5 \%)$. This showed that for organic pizza positive moral norm significantly increased prediction of intent and negative moral norm (doing the wrong thing when buying organic pizza) did not.

insert table 7 here

Comparison of regressions where affective and cognitive attitudes were separate and combined showed there were no differences between the two models in people's buying intent or their contribution to predict intent (table 8).

Insert table 8 here

\section{Attitudes and moral norms}

To check whether moral norms had an independent causal influence on attitude, hierarchical regression of attitudes (affective and cognitive combined) on beliefs and moral norms (positive and negative separately) was undertaken. Results showed (table 9) that the regression of attitude on general beliefs, belief on price, appearance, positive moral norms and negative moral norms (adjusted $R^{2}=0.56, F(5,275)=72.62, p<0.0001$ ) revealed significant independent effects for general beliefs $(\beta=0.47, \mathrm{df}=280, \mathrm{p}<0.001)$, price $(\beta=-0.11, \mathrm{df}=280, \mathrm{p}<0.01)$, and positive moral norm $(\beta=0.35, \mathrm{df}=280, p<0.001)$ but not for appearance $(\beta=-0.02, \mathrm{df}=280, \mathrm{~ns})$ or negative moral norm $(\beta=-0.05, d f=280, n s)$. The increment in explained variance (change in $R^{2}$ ) from the first to second stage revealed it was significant $(p<0.0001)$ for attitude $(8 \%)$. This showed that for organic apple positive moral norm significantly increased prediction of attitude whereas negative moral norm did not.

.. Insert table 9 here

Similar regression for organic pizza showed (table 10) that the regression of attitude on general beliefs, appearance, positive moral norms and negative moral norms (adjusted $R^{2}=0.53, F(4,276)=$ $80.32, p<0.0001$ ) revealed significant independent effects for general beliefs $(\beta=0.30, d f=280, p<$ 0.001 ), positive moral norm $(\beta=0.46, d f=280, p<0.001)$, negative moral norm $(\beta=-0.19, d f=280$, 
$p<0.001)$ and appearance $(\beta=-0.09, d f=280, p=0.05)$. The increment in explained variance (change in $\mathrm{R}^{2}$ ) from the first to second stage revealed it was significant $(p<0.0001)$ for attitude (14\%). This showed that for organic pizza both positive moral norms and negative moral norms significantly increased prediction of attitude.

...insert table 10 here

\section{Discussion}

The regression analyses supported the overall structure of the conceptual model which included the measure of moral norms and affective attitude. The results of the study were in line with other studies that have shown an independent predictive effect of perceived moral obligation on behavioral intentions (Beck and Ajzen, 1991; Gorsuch and Ortberg, 1983; Parker et al., 1995; Pomazal and Jaccard, 1976; Schwartz and Tessler, 1972) and on attitudes (Raats, Shepherd and Sparks, 1995; Sparks et al., 1995; Sparks and Shepherd, 2002). In our study $60 \%$ of the variance in intention was explained for fresh produce and $39 \%$ for processed produce. Previous studies that included some form of moral or personal norm accounted for 40 to $78 \%$ of the variance in intention (Sparks and Shepherd, 2002; Thøgersen, 2002; Raats et al., 1995). However, for organic foods it is the positive moral norm that was an important predictor as opposed to negative moral norm or moral obligations as in all previous studies. That is, in relation to buying organic foods people's moral and ethical attitudes such as what is the right thing to do, contributing to something better and makes me feel like a better person seem to play an important role in how they make choices between organic and its conventional counterpart rather than negative moral norms such as whether they feel guilty for buying organic, going against their principles or whether they think it is a morally wrong thing to do, that influenced their choice. This suggests that the moral feelings associated with buying organic food is more to do with doing something positive rather than feeling bad or not bad for doing that thing. This implies that although moral norms may play a part in many different domains such as cheating and giving blood the mechanisms by which influence occurs may differ and depend on the domain in question.

In addition to predicting intention to buy, positive moral norm was shown to have an independent contribution route to attitude, for both fresh and processed organic products. In addition moral negative norm contributed to the attitudes towards processed organic produce but not for fresh organic produce. It could be argued that making a positive contribution, feeling good about it and seeing it as a morally right thing may be equally applicable to all organic products whereas negative moral attitudes such as feeling it is not the right thing to do, goes against one's principles and feeling guilty is relevant only to processed foods and not to fresh ones. This could be because for some people the act of processing in some way contradicts what organic is and may feel that it is a morally wrong thing to do and feel guilty about buying such a product. These results confirm Raats et al.'s argument that some food choices cannot be sufficiently accounted for by people's utility motives such as risks and benefits, but we also have to take into account what they consider to be morally right and wrong. This study corroborates previous research and offers further evidence for the inclusion of moral norms as a predictor variable both for intention and attitude in the theory of planned behaviour, for some domains.

Studies using TPB differ in the way they measure attitudes. In some only a general single measure is used. Often a composite measure of several adjective pairs, some referring to cognitive judgments (wise - foolish) and others to affective judgments (pleasant - unpleasant) are used (Conner and Sparks, 1996). This study not only addressed both the cognitive and affective components but investigated their unique contribution to the model by looking at them separately. Results showed that affective attitude was a better predictor of intent than cognitive attitude, for both fresh and processed organic foods. In fact for processed organic pizza it is the affect rather than the cognitive component that made a significant contribution to intention. This suggests that people evaluate 
food related behaviors not only in terms of costs and benefits but also in terms of the positive and negative feelings generated. However, the predictive contribution of attitude to intent was the same regardless of whether affect and cognition were considered separately or combined, similar to the results obtained by Ajzen and Driver (1991) for leisure activities. This suggests that here too affect and cognition combine in a compensatory way as argued by Ajzen and Driver (1991). That is, the perceived costs of buying organic products can be offset by positive feelings it produces and negative affects offset by perceived benefits. The results highlight the importance of including both affective and cognitive components of attitudes especially in food choice where affect plays an important role in buying intention.

The regression models for both organic fresh and processed foods suggest that subjective norm is a good predictor of buying intention. This is in line with previous research in this area (Armitage and Conner, 2001). However, although perceived behavioural control (PBC) was a good predictor for the organic fresh product it was not for the organic processed product. In both cases PBC was measured using two items addressing how easy it was to buy these products and how possible it was to buy them. The means and standard deviations of PBC for organic fresh apple and organic pizza showed that people perceived themselves as having more control over buying organic apples than organic pizza. It could be that despite organic ready-to-cook pizza being readily available in the supermarkets it may not be very prominent and so people may perceive buying such pizzas as being outside their control. This would explain their lowered perception of control relating to organic pizza. A measure of availability may need to be added to explain such behavior.

On the whole the regression models explained more variance in the purchase of fresh organic apple than in processed organic pizza. This could be due to the participants having less experience with processed organic products compared to fresh ones. Alternatively it could be because for some people processing may be incongruent with organic foods where they associate positive qualities such as natural and healthy with organic and negative qualities such as has additives and chemicals with processed foods (Bredahl, 1999). More research with different processed foods is needed before any definite conclusion may be reached on this.

\section{References}

Ajzen, I. (1991). The theory of planned behavior. Organizational Behavior and Human Decision Processes, 50, 179-211.

Ajzen, I., \& Driver, B. L. (1991). Prediction of leisure participation from behavioral, normative, and control beliefs: An application of the Theory of Planned Behavior. Leisure Sciences, 13, 185-204.

Ajzen, I., \& Fishbein, M (1980). Understanding attitudes and predicting social behavior. Englewood Cliffs, NJ: Prentice-Hall.

Ajzen, I., \& Fishbein, M. (2000). Attitudes and the attitude-behavior relation: reasoned and automatic processes. European Review of Social Psychology, 11, 1-33.

Ajzen, I., \& Timko, C. (1986). Correspondence between health attitudes and behavior. Basic and Applied Social Psychology, 7(4), 259-276.

Armitage, C. J. \& Conner, M. (1999). Predictive validity of the theory of planned behavior: the role of questionnaire format and social desirability. Journal of Community and Applied Scial Psychology, 9, 261-272.

Armitage, C. J. \& Conner, M. (2001). Efficacy of the theory of planned behaviour: a metaanalytic review. British Journal of Social Psychology, 40, 471-499. 
Bagozzi, R. P. (1989). An investigation of the role of affect and moral evaluations in the purposive behaviour model of attitude. British Joural of Social Psychology, 25, 95-107.

Biddle, B.J., Bank, B. J., \& Slavings, R. L. (1987). Norms, preferences, identities, and retention decisions. Social Psycholgy Quarterly, 50, 322-337.

Beale, D. A., \& Manstead, A. S. R. (1991). Predicting mothers' intentions to limit frequency of infants' sugar intake: testing the Theory of Planned Behavior. Journal of Applied Social Psychology, 25, 285-301.

Bredahl, L. (1999). Consumers' cognitions with regard to genetically modified foods. Results of a qualitative study in four countries. Appetite, 33, 343-360.

Beck, L., \& Ajzen, I. (1991). Predicting dishonest actions using the Theory of Planned Behavior. Journal of Research in Personality, 25, 285-301.

Black , J.S., Stern, P.C., \& Elworth, J.T. (1985). Personal and contextual influences on household energy adaptaions. Journal of Applied Psychology, 70, 3-21.

Brinberg, D., \& Durand, J. (1983). Eating at fast-food restaurants: an analysis using two behavioral intention models. Journal of Applied Social Psychology, 13, 459-472.

Commission of the European Communities (2004). European Action Plan for Organic Food and Farming. Commission of the European Communities, Brussels SEC(2004) 739.

Charng, H.-W., Piliavin, J.A., \& Callero, P.L. (1988). Role identity and reasoned action in the prediction of repeated behavior. Social Psychology Quarterly, 51, 303-317.

Conner, M., \& Sparks, P. (1996). The Theory of Planned Behaviour and health behaviours. In M. Conner \& P. Norman (Eds.), Predicting Health Behaviour: Research and Practice with Social Cognition Models. Buckingham: Open University Press.

Esses, V. M., \& Maio, G. R. (2002). Expanding the assessment of attitude components and structure: the benefits of open-ended measures. European Review of Social Psychology, 12, 71-101.

Gorsuch, R. L., \& Ortberg, J. (1983). Moral obligation and attitudes: their relation to behavioral intentions. Journal of Personality and Social Psychology, 44(5), 1025-1028.

Guagnano, G.A., Stern, P.C., \& Dietz, T. (1995). Influences on attitude-behavior relationships. A natural experiment with curbside recycling. Environment and Behavior, 27, 699718.

Heberlein, T. A. (1972). The land ethic realized: Some social psychological explanations for changing environmental attitudes. Journal of Social Issues, 28, 79-87.

Klont, R. (1999). Growing organic foods. World Ingredients (May/June), 40-44.

Lloyd, H., Paisley, C., \& Mela, D. J. (1993). Changing to a low fat diet: attitudes and beliefs of UK consumers. European Journal of Clinical Nutrition, 47, 361-373.

Manstead, A.S.R., Plevin, C.E., \& Smart, J.L. (1983). Predicting and understanding mothers' infant feeding intentions and behavior. Journal of Personality and Social Psychology, 44, 657-671.

Manstead, A.S.R., Plevin, C.E., \& Smart, J.L. (1984). Predicting mothers' choice of infant feeding method. British Journal of Social Psychology, 23, 223-231.

Manstead, A. S. R. (2000). The role of moral norm in the attitude-behavior relation. In D. J. Terry and M. A. Hogg (Ed.), Attitudes, Behavior and Social Context: the Role of Norms and Group Membership (pp. 11-30). Lawrence Erlbaum Associates, Inc. NJ.

Parker, D., Manstead, A. S. R., \& Strandling, S. G. (1995). Extending the Theory of Planned Behaviour: the role of personal norm. British Journal of Social Psychology, 34(2), 127-138. 
Pomazal, R. J., \& Jaccard, J. J. (1976). An informational approach to altruistic behavior. Journal of Personality and Social Psychology, 33, 317-326.

Paisley, C. M., \& Sparks, P. (1998). Expectation of reducing fat intake: The role of perceived need within the theory of planned behavior. Psychology and Health, 13, 341-353.

Raats, M., Shepherd, R., \& Sparks, P. (1995). Including moral dimensions of choice within the structure of the Theory of Planned Behavior. Journal of Applied Social Psychology, 25(6), 484494.

Richard, R. (1994). Regret is what you get : The impact of anticipated feelings and emotions on human behavior. Unpublished doctoral dissertation, University of Amsterdam.

Richard, R., van der Pligt, J., \& de Vries, N. (1995). Anticipated affective reactions and prevention of AIDS. British Journal of Social Psychology, 34, 9-21.

Schwartz, S.H., \& Tessler, R.C. (1972). A test of a model for reducing measured attitudebehavior discrepancies. Journal of Personality snd Social Psychology, 24, 225-236.

Sheppard, B., H, Hartwick, J., \& Warshaw, P., R. (1988). The Theory of Reasoned Action: a meta-analysis of past research with recommendations for modifications and future research. Journal of Consumer Research, 15, 325-343.

Shepherd, R., Magnusson, M. K., \& Sjoden, P. O. (2005). Determinants of consumer behavior related to organic foods. Ambio, 34, 349-356.

Sparks, P., Hedderley, D., \& Shepherd, R. (1992). An investigation into the relationship between perceived control, attitude variability and the consumption of two common foods. European Journal of Social Psychology, 22, 55-71.

Sparks, P., \& Shepherd, R. (1992). Self-identity and the Theory of Planned Behavior: assessing the role of self-identification with "green consumerism". Social Psychology Quarterly, 55 (4), 388-399.

Sparks, P., \& Shepherd, R. (2002). The role of moral judgments within expectancy-valuebased attitude-behavior models. Ethics \& Behavior, 12(4), 299-321.

Sparks, P., Shepherd, R., \& Frewer, L. J. (1995). Assessing and structuring attitudes toward the use of gene technology in food production: the role of perceived ethical obligation. Basic and Applied Social Psychology, 16(3), 267-285.

Schwartz, S. H., \& Tesser, R. C. (1972). A test of a model for reducing measured attitudebehavior discrepancies. Journal of Personality and Social Psychology, 24, 228-236.

Thøgersen, J. (1996). Recycling and morality. A critical review of the literature. Environment and Behavior, 28, 536- 558.

Thøgersen, J. (1999). The ethical consumer. Moral norms and packaging choice. Journal of Consumer Policy, 22, 439-460.

Thøgersen, J. (2002). Direct experience and the strength of the personal norm-behavior relationship. Psychology \& Marketing, 19(10), 881-893.

Towler, G., \& Shepherd, R. (1992). Modification of Fishbein and Ajzen's theory of reasoned action to predict chip consumption. Food Quality and Preference, 3, 37-45.

van dan Putte, H. ( 1993). On the theory of reasoned action, unpublished doctoral dissertation, University of Amsterdam. 
Table 1: Beliefs - Means and standard deviations

\begin{tabular}{|c|c|c|}
\hline & $\begin{array}{c}\text { Apple mean } \\
\text { (sd) }\end{array}$ & $\begin{array}{c}\text { Pizza mean } \\
\text { (sd) }\end{array}$ \\
\hline \multirow[t]{2}{*}{ Price } & 6.0 & 6.0 \\
\hline & (1.1) & $(1.2)$ \\
\hline \multirow[t]{2}{*}{ Chemicals } & 6.0 & 5.7 \\
\hline & $(1.2)$ & $(1.2)$ \\
\hline \multirow[t]{2}{*}{ Healthy } & 5.7 & 5.2 \\
\hline & $(1.3)$ & $(1.6)$ \\
\hline \multirow[t]{2}{*}{ Taste } & 5.0 & 4.5 \\
\hline & $(1.6)$ & $(1.6)$ \\
\hline \multirow[t]{2}{*}{ Appearance } & 3.8 & 3.9 \\
\hline & (1.4) & (1.4) \\
\hline \multirow[t]{2}{*}{ Environment } & 5.8 & 5.3 \\
\hline & $(1.3)$ & (1.4) \\
\hline \multirow[t]{2}{*}{ Natural } & 5.7 & 5.2 \\
\hline & (1.4) & (1.5) \\
\hline \multirow[t]{2}{*}{ Trust } & 5.3 & 4.9 \\
\hline & (1.4) & (1.4) \\
\hline
\end{tabular}


Table 2: Factor analysis of beliefs concerning organic apples

\begin{tabular}{lcc}
\hline & Factor 1 & Factor 2 \\
\hline Price & 0.24 & 0.82 \\
\hline Chemicals & 0.84 & 0.19 \\
\hline Healthy & 0.87 & 0.07 \\
\hline Taste & 0.57 & -0.43 \\
\hline Appearance & 0.17 & -0.62 \\
\hline Environment & 0.87 & -0.02 \\
\hline Natural & 0.86 & 0.05 \\
\hline Trust & 0.65 & -0.38 \\
\hline Variance explained & $49 \%$ & $17 \%$ \\
\hline Correlations between components & & -0.18 \\
\hline
\end{tabular}

Table 3: Factor analysis of beliefs concerning organic ready-to-cook pizza

\begin{tabular}{lcc}
\hline & Factor 1 & Factor 2 \\
\hline Price & 0.70 & -0.40 \\
\hline Chemicals & 0.87 & 0.02 \\
\hline Healthy & 0.68 & 0.24 \\
\hline Taste & 0.72 & 0.33 \\
\hline Appearance & 0.03 & 0.87 \\
\hline Environment & 0.87 & 0.11 \\
\hline Natural & 0.86 & 0.13 \\
\hline Trust & 0.68 & 0.37 \\
\hline Variance explained & $57 \%$ & $15 \%$ \\
\hline Correlation between components & & 0.27 \\
\hline
\end{tabular}


Table4: Means and standard deviations of, correlation between, and the reliability coefficients of the principal constructs related to organic apple and organic pizza

\begin{tabular}{lcccccc}
\hline TPB variables & $\begin{array}{c}\text { Means (SD) } \\
\text { for Apple }\end{array}$ & Alpha & $\begin{array}{c}\text { Correlation } \\
\text { with } \\
\text { intention }\end{array}$ & $\begin{array}{c}\text { Means (SD) } \\
\text { for Pizza }\end{array}$ & $\begin{array}{c}\text { Alpha } \\
\text { Correlati } \\
\text { on with } \\
\text { intention }\end{array}$ \\
\hline Intention & $3.8(2.2)$ & 0.92 & - & $2.4(1.8)$ & 0.82 & - \\
Attitude (combined) & $5.2(1.3)$ & 0.90 & 0.70 & $4.7(1.3)$ & 0.85 & 0.56 \\
Affective attitude & $4.9(1.6)$ & 0.95 & 0.68 & $4.3(1.6)$ & 0.97 & 0.53 \\
Cognitive attitude & $5.6(1.3)$ & 0.86 & 0.60 & $5.0(1.3)$ & 0.87 & 0.51 \\
Subjective Norm & $3.8(1.3)$ & 0.64 & 0.56 & $3.2(1.2)$ & 0.67 & 0.48 \\
PBC & $5.1(1.5)$ & 0.52 & 0.45 & $3.8(1.5)$ & 0.56 & 0.16 \\
Moral positive & $3.9(1.7)$ & 0.90 & 0.65 & $3.4(1.9)$ & 0.92 & 0.56 \\
Moral negative & $1.8(1.0)$ & 0.76 & -0.14 & $1.9(1.1)$ & 0.79 & -0.07 \\
\hline
\end{tabular}

Table 5: Multiple hierarchical regressions of intentions to purchase organic apples on affective attitudes, cognitive attitudes, subjective norms, perceived behavioral control and moral norms $(n=281)$

\begin{tabular}{lllllll}
\hline & & $\mathrm{R}$ & Adj. $\mathrm{R}^{2}$ & Inc. to $\mathrm{R}^{2}$ & $\mathrm{~F}_{\text {change }}$ & Final $\beta$ \\
\hline \multirow{2}{*}{ Stage 1 } & $\begin{array}{l}\text { Affective } \\
\text { Cognitive }\end{array}$ & & & & & $0.29^{* * *}$ \\
& Perceived control & & & & & $0.11^{*}$ \\
& Subjective norm & 0.74 & 0.55 & 0.55 & $85.25^{* * *}$ & $0.10^{*}$ \\
Stage 2 & Moral positive & & & & & $0.18^{* * *}$ \\
& Moral negative & 0.78 & 0.60 & 0.05 & $17.95^{* * *}$ & 0.01 (ns) \\
\hline
\end{tabular}

${ }^{*} \mathrm{p}<0.05, * * \mathrm{p}<0.01, * * * \mathrm{p}<0.001$ 
Table 6: Multiple hierarchical regressions of intentions to purchase organic apples on combined emotional and cognitive attitudes, subjective norms, perceived behavioral control and moral norms $(n=281)$

\begin{tabular}{lllllll} 
& & $R$ & $R^{2}$ & Inc. to $R^{2}$ & $F_{\text {change }}$ & Final $\beta$ \\
\hline Stage 1 & Attitude & & & & & $0.37^{* * *}$ \\
& $\begin{array}{l}\text { Perceived } \\
\text { control }\end{array}$ & & & & & $0.18^{* * *}$ \\
& Subjective norm & 0.74 & 0.55 & 0.55 & $112.58^{* * *}$ & $0.11^{*}$ \\
& Moral positive & & & & & $0.31^{* * *}$ \\
Stage 2 & Moral negative & 0.78 & 0.59 & 0.05 & $17.82^{* * *}$ & 0.01 (ns) \\
& & & & & & \\
\end{tabular}

$\mathrm{p}<0.05, * * \mathrm{p}<0.01, * * * \mathrm{p}<0.001$

Table7: Multiple hierarchical regressions of intentions to purchase organic ready-to-cook pizza on affective attitudes, cognitive attitudes, subjective norms, perceived behavioral control and moral norms ( $n=281)$

\begin{tabular}{|c|c|c|c|c|c|c|}
\hline & & $R$ & Adj. $R^{2}$ & Inc. to $\mathrm{R}^{2}$ & $F_{\text {change }}$ & Final $\beta$ \\
\hline \multirow{4}{*}{ Stage 1} & Affective & & & & & $0.18^{* *}$ \\
\hline & Cognitive & & & & & 0.10 (ns) \\
\hline & $\begin{array}{l}\text { Perceived } \\
\text { control }\end{array}$ & & & & & 0.02 (ns) \\
\hline & Subjective norm & 0.60 & 0.35 & 0.36 & $38.42 * * *$ & $0.16^{* *}$ \\
\hline \multirow[t]{2}{*}{ Stage 2} & Moral positive & & & & & $0.31^{* * *}$ \\
\hline & Moral negative & 0.64 & 0.39 & 0.05 & $10.85^{* * *}$ & -0.07 (ns) \\
\hline
\end{tabular}

$* p<0.05, * * p<0.01, * * * p<0.001$ 
Table 8: Multiple hierarchical regressions of intentions to purchase organic ready-to-cook pizza on attitudes, subjective norms, perceived behavioral control and moral norms $(n=281)$

\begin{tabular}{|c|c|c|c|c|c|c|}
\hline & & $\mathrm{R}$ & Adj. $R^{2}$ & Inc. to $\mathrm{R}^{2}$ & $\mathrm{~F}_{\text {change }}$ & Final $\beta$ \\
\hline \multirow[t]{5}{*}{ Stage 1} & Attitude & & & & & $0.27^{* * *}$ \\
\hline & Perceived & & & & & 0.02 (ns) \\
\hline & control & & & & & \\
\hline & Subjective & 0.60 & 0.35 & .36 & $51.40 * * *$ & $0.16^{* *}$ \\
\hline & norm & & & & & \\
\hline \multirow[t]{2}{*}{ Stage 2} & Moral positive & & & & & $0.3^{* * *}$ \\
\hline & Moral negative & 0.64 & 0.39 & .05 & $10.79 * * *$ & -0.07 (ns) \\
\hline
\end{tabular}

Table 9: Multiple hierarchical regressions of attitude to organic apples on beliefs and moral norms ( $n=281)$

\begin{tabular}{|c|c|c|c|c|c|c|}
\hline & & $\mathrm{R}$ & Adj. $R^{2}$ & $\begin{array}{l}\text { Inc. to } \\
\mathrm{R}^{2}\end{array}$ & $F_{\text {change }}$ & Final $\beta$ \\
\hline \multirow[t]{3}{*}{ Stage 1} & $\begin{array}{l}\text { Beliefs about } \\
\text { org. apples }\end{array}$ & & & & & $0.47^{* * *}$ \\
\hline & Price & & & & & $-0.11 * *$ \\
\hline & Appearance & 0.70 & 0.49 & 0.49 & $89.0 * * *$ & $-0.02(n s)$ \\
\hline \multirow[t]{2}{*}{ Stage 2} & Moral positive & & & & & $0.35^{* * *}$ \\
\hline & Moral negative & 0.75 & 0.56 & 0.08 & $25.0 * * *$ & -0.05 (ns) \\
\hline
\end{tabular}

${ }^{*} \mathrm{p}<0.05, * * \mathrm{p}<0.01, * * * \mathrm{p}<0.001$

Beliefs (alpha $=0.88)-$ Chemical, health, trust, natural, taste and environmental. 
Table 10: Multiple hierarchical regressions of attitude to ready-to-cook pizza on beliefs and moral norms ( $n=281)$

\begin{tabular}{|c|c|c|c|c|c|c|}
\hline & & \multicolumn{5}{|c|}{ Inc. to } \\
\hline & & $\mathrm{R}$ & $\operatorname{Adj} . R^{2}$ & $\mathrm{R}^{2}$ & $F_{\text {change }}$ & Final $\beta$ \\
\hline \multirow[t]{2}{*}{ Stage 1} & $\begin{array}{l}\text { Beliefs about } \\
\text { org. pizza }\end{array}$ & & & & & $0.30 * * *$ \\
\hline & Appearance & 0.63 & 0.39 & 0.40 & $91.05^{* * *}$ & -.0 .09 (ns) \\
\hline \multirow[t]{2}{*}{ Stage 2} & Moral positive & & & & & $0.46 * * *$ \\
\hline & Moral negative & 0.73 & 0.53 & 0.14 & $42.44^{* * *}$ & $-0.19 * * *$ \\
\hline
\end{tabular}

$* \mathrm{p}<0.05, * * \mathrm{p}<0.01, * * * \mathrm{p}<0.001$

Beliefs (alpha $=.89)-$ Health, price, chemical, trust, natural, environmental, taste 